\title{
VALOR DA ÁGUA VIRTUAL DE HORTALIÇAS COMERCIALIZADA EM BENEVIDES - PA
}

\author{
BARROS, Karina Fabíola Glins de ${ }^{1}$ \\ SANTANA, Antônio Cordeiro de ${ }^{1}$ \\ MARTINS, Cynthia Meireles ${ }^{1}$ \\ CAMPOS, Pedro Silvestre da Silva ${ }^{1}$
}

\begin{abstract}
RESUMO: A água tem importância para toda a biota da Terra, sendo que o Brasil possui um grande potencial hídrico com índices pluviométricos em mais de $90 \%$ do seu território. No entanto, esse potencial tem sido pouco valorizado, pois parte dessa água está sendo exportada na forma virtual sem valor monetário. Hortaliças como coentro e alface demandam muita água durante todo o ciclo de vida com teor de umidade sempre próximo a $100 \%$. A pesquisa foi realizada no município de Benevides-PA, região metropolitana de Belém, estado do Pará. Para determinar o volume de água virtual das hortaliças, a irrigação foi monitorada durante 35 dias, tempo para completar o ciclo de vida da cultura. Feito isso, calculou-se o volume da evapotranspiração da cultura, o que resultou na quantidade d'água que é perdida para o ambiente e não é computada no volume de água virtual. A quantidade de água gasta na irrigação foi de 137.32 litros, com uma perda de $15,01 \%$ do volume para o ambiente, o que resultou $116.710,44$ litros de água virtual gasta na produção. As hortaliças antes vendidas por $\mathrm{R} \$ 0,80$ e $\mathrm{R} \$ 3,00$ por maço de coentro e $\mathrm{R} \$ 0,70$ e $\mathrm{R} \$ 2,00$ por maço de alface, respectivamente no atacado e varejo, tiveram um aumento de $\mathrm{R} \$ 0,08 / \mathrm{mc}$ no preço do coentro e $\mathrm{R} \$ 0,11 / \mathrm{mc}$ no preço da alface. Portanto, o valor de água virtual embutido no coentro e na alface por maço foi 8,25 litros e 10,97 litros, respectivamente.
\end{abstract}

Palavras chaves: Água virtual. Preço. Comercialização. Hortaliças.

SUMMARY: Water is important for the whole biota of the Earth, and Brazil has a large hydro potential with rainfall in more than $90 \%$ of its territory. However, this potential has been undervalued because of this water is being exported in virtually no monetary value. Vegetables like cilantro and lettuce require a lot of water throughout the life cycle of moisture content always close to $100 \%$. The survey was conducted in the municipality of Benevides, PA, metropolitan region of Belém, Pará state. To determine the virtual water volume of vegetables, irrigation was monitored for 35 day's time to complete the crop cycle of life. Then, it calculated the volume of crop evapotranspiration, which resulted in the amount of water that is lost to the environment and is not computed in the volume of virtual water. The amount of water in the spent irrigation was 137.32 liters, with a 15,01\% loss of volume to the environment, which resulted $116.710,44$ liters of water spends at virtual production. The vegetables before sold for R\$ 0,80 and $\mathrm{R} \$ 3,00$ per bunch of cilantro and $\mathrm{R} \$ 0,70$ and $\mathrm{R} \$ 2,00$ per head of lettuce, respectively wholesale and retail, we had an increase of $\mathrm{R} \$ 0,08 / \mathrm{mc}$ in price coriander and $\mathrm{R} \$ 0,11 / \mathrm{mc}$ in the price of lettuce. Therefore, the embedded virtual water value in the cilantro and lettuce per pack was 8,25 liters and 10,97 liters, respectively.

Keywords: Virtual water. Price. Marketing. Vegetables.

\section{INTRODUÇÃO}

A água é um patrimônio natural da humanidade que a cada dia se torna mais dispendiosa, pois, a despeito da sua importância para a vida na Terra, normalmente é usada de maneira irracional nos processos produtivos da agricultura e da indústria. Em virtude dessa realidade, tornou-se ponto de discussão nas últimas décadas, sendo que o enfoque parte de pressupostos político, social e econômico, que são vertentes dependentes d'água para alcançar o desenvolvimento (OJIMA et al., 2008).

\footnotetext{
${ }^{1}$ Universidade Federal Rural da Amazônia - UFRA
} 
Contudo, a falta de conhecimento sobre suas contribuições para as funções ecossistêmicas, pode comprometer as populações bióticas, reservas ecológicas e o ciclo natural da água (DOWBOR, 2005). Vale frisar que além de ser um elemento vital para conservação dos ecossistemas, pode gerar perdas na produtividade socioeconômica, que geralmente, acarretam altos custos para a população (DOWBOR, 2005).

Dos $100 \%$ de reservas d'água que o planeta possui $98 \%$ é água salgada e apenas $2 \%$ é água doce, destes $87 \%$ está indisponível, preso nas calotas polares e geleiras, e outra parte se encontra na atmosfera, áreas subterrâneas e nos seres vivos (DOWBOR, 2005). A parte mínima se encontra na superfície, disponível em rios, lagos e lagoas.

Esta água disponível será um desafio para suportar o demanda global. Estima-se um crescimento na demanda de 7,2 bilhões para 9,6 bilhões em 2050 (FAO, 2013). Desta maneira, a gestão do recurso hídrico será um ponto estratégico para que a água não seja exaurida com o aumento da população.

O Brasil é um país com grande abundância hídrica, pois recebe índices pluviométricos em mais de $90 \%$ do seu território, ficando entre 1.000 a mais de $3.000 \mathrm{~mm} / \mathrm{ano}$, além de uma rica rede de drenagem perene, que pode ser considerado como uma potência hídrica (REBOUÇAS, 2003).

Contudo, esse potencial hídrico tem sido pouco valorizado, em função da grande rede de exportação de água na forma virtual, dentre as quais, na produção dos alimentos (MEIO AMBIENTE, 2010), onde o Brasil se enquadra como o maior exportador (CARMO et al., 2006).

Vale frisar que a água utilizada no ciclo biológico dessas plantas, desses alimentos, não está sendo computada para formar o preço final dos produtos ofertados, com isso, a sociedade deixa de se apropriar do benefício do uso sustentável da água e, ao mesmo tempo, incorpora o custo ambiental da comercialização da água virtual que permanece no produto até o mercado consumidor.

A escolha desse tema tem grande relevância estratégia para futuras pesquisas, sendo esse um trabalho pioneiro sobre água virtual nas hortaliças. Tem importância também ambiental, dado que os recursos naturais são limitados, em especial, o recurso hídrico em termos de quantidade e qualidade, o que impõe responsabilidade de utilização racional para atender às gerações presente e futura.

As hortaliças estudadas nesse trabalho serão as herbáceas, ou seja, aquelas cujas partes comerciáveis e utilizáveis localizam-se acima do solo (FILGUEIRA, 2013), têm suas folhas como parte consumida (FURLANI; PURQUEIRO, 2010) e foram escolhidas em virtude de serem as mais exigentes em água. Portanto, é necessário manter o seu teor de água próximo de $100 \%$ até o momento da colheita (FILGUEIRA, 2013).

Cabe notar que um dos propósitos de valorar a água é contribuir para diminuir sua perda pelo comércio virtual, que deixou de ser um bem livre como considerava a economia neoclássica. A partir de sua escassez e grande utilidade deve ser valorada para que entre na componente dos custos de produção agropecuária.

Sendo assim, considerando a magnitude da água virtual na produção de hortaliças e o fato do município de Benevides, estado do Pará, ter representatividade na produção dessas culturas, buscou-se determinar seu valor monetário, a partir da determinação da quantidade de água transportada nas hortaliças coentro (Coriandrum sativum) e alface (Lactuca sativa), produzidas nesse município que abriga o cultivo de hortaliças por pequenos agricultores familiares (IBGE, 2014).

\section{DEFINIÇÃo DE ÁGUA VIRTUAL}

Água virtual é a água que está contida em todos os alimentos e até o momento não está sendo 
adicionada ao preço do produto. O conceito da metáfora água virtual foi criado na década de 1990 no seminário da Escola de Estudos Orientais e Africanos (SOAS) por Allan (2003) e é recente no Brasil, sendo uma forma de desenvolver estratégias de produção para a utilização racional desse recurso hídrico.

Essa água implica monitorar todas as etapas do processo de produção do produto estudado, considerando todos os fatores ambientais da região, dentre eles o clima e o processo de evapotranspiração (CARMO et al., 2007). Além disso, são necessárias metodologias específicas e estratégias para conseguir monitorar a água que está entrando no sistema produtivo dos alimentos, a exemplo do volume irrigado.

A quantidade de água que é utilizada para produção de um tipo de grão, hortaliça ou qualquer outro produto alimentício pode prejudicar o potencial hídrico da região que é cultivada, ocasionando uma possível escassez (ALLAN, 2003). Por isso, propõem-se para diminuir perdas que as lavouras sejam cultivadas de acordo com a sua necessidade hídrica. Assim, o que define o que e onde produzir é a quantidade de água disponível (CARMO et al., 2006).

Ao determinar as vocações dos espaços para as culturas com grandes necessidades hídricas, não se pode deixar de considerar e analisar as situações locais como: a presença de reservas indígenas; áreas de conservação ambiental; mata pouco povoada, como no caso da região norte do Brasil (CARMO et al., 2006) e outras comunidades tradicionais, a exemplo de pescadores e ribeirinhos, que dependem totalmente da água para sobrevivência.

Vale frisar que a forma como essa água está sendo exportada sem preço, pode levar ao esgotamento do recurso em diversos locais de produção onde não há o uso racional e sustentável da água. Ainda, além das comunidades tradicionais o pequeno agricultor pode ser afetado diretamente com a diminuição da demanda d'água, visto que com uma crise hídrica o pequeno agricultor tem menos chances no mercado que o grande agricultor que possui mais tecnologias para obter e administrar a água.

Portanto, Allan (2003) argumenta que não basta saber quanto está sendo perdido de recurso hídrico, resta saber também, para onde ele está indo e no que interfere na segurança alimentar.

\section{METODOLOGIA}

\subsection{Localização da área de estudo}

Benevides pertence à mesorregião Metropolitana de Belém, situa-se a Leste do município de Santa Izabel do Pará e a Oeste dos municípios de Ananindeua e Marituba (IDESP, 2011). Possui uma área territorial de 187,826 ( $\left.\mathrm{km}^{2}\right)$ e densidade demográfica 274,99 (hab/km²) (IBGE, 2014).

O clima do município é megatérmico úmido, temperatura elevada durante todo o ano com média de $26^{\circ} \mathrm{C}$ (IDESP, 2011). Os meses mais quentes são os de setembro a dezembro, sendo que, nessa época, a média máxima é acima de $32^{\circ} \mathrm{C}$. Com regime pluviométrico elevado, chega a ultrapassar, normalmente, os $2.500 \mathrm{~mm} /$ ano e a umidade relativa do ar gira em torno de 85\% (IDESP, 2011).

Existem 18 comunidades agrícolas em Benevides, de acordo com o relatório técnico do Departamento de Agricultura Municipal de Benevides que recebem o apoio da Empresa de Assistência Técnica e Extensão Rural - EMATER e do Sindicato dos Trabalhadores Rurais de Benevides. Benevides é importante na produção de horticultura e no abastecimento do mercado da região metropolitana de BelémRMB.

Para o monitoramento da quantidade de água utilizada em cada canteiro foi selecionada uma propriedade de referência de produção de hortaliças no município, cujo proprietário aceitou colaborar com o trabalho.

Nucleus,v.15,n.1,abr.2018 
Nessa propriedade são cultivadas as seguintes hortaliças: coentro (Coriandrum sativum), alface (Lactuca sativa) e jambú (Spilanthes acmella), este último, típico da região Norte do Brasil.

A propriedade possui 50 canteiros, sendo 34 de coentro, 10 de alface e 6 de jambú, são equidistantes, com 32,28 metros de comprimento e 1,45 metro de largura (Figura 1).

Figura 1 - Canteiros com aproximadamente 32,28 $\mathrm{m}$ de comprimento e 1,45 $\mathrm{m}$ de largura

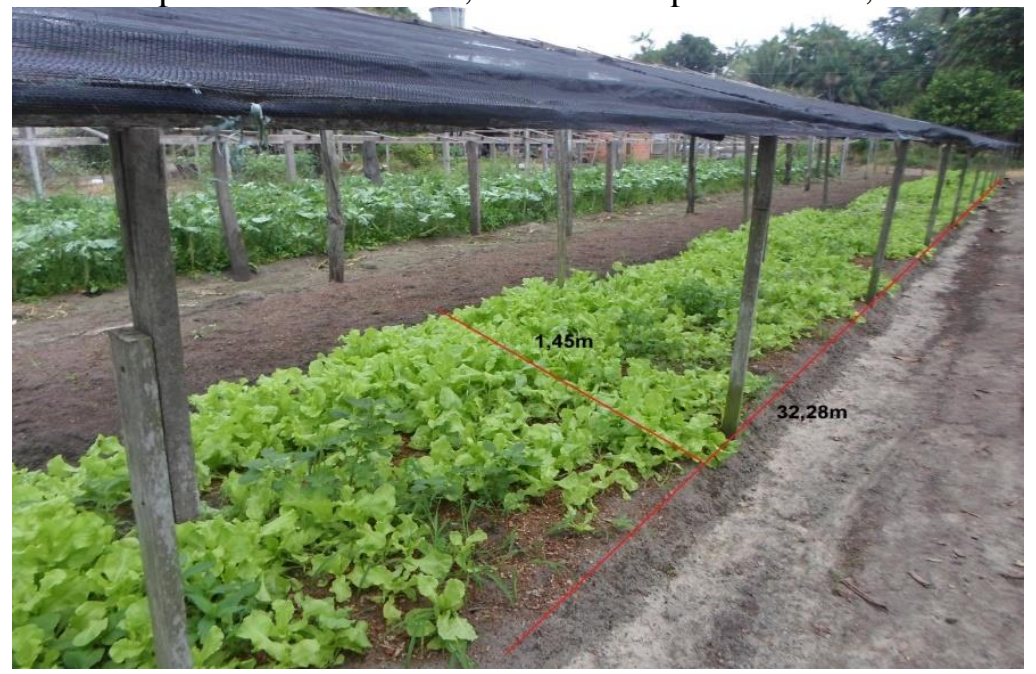

Fonte: Arquivo Pessoal

\subsection{Monitoramentos das irrigações}

O monitoramento foi realizado no período de trinta e cinco dias, tendo início no dia 26 de setembro e finalizado no dia 30 de outubro de 2014, tempo de crescimento médio das hortaliças: alface e coentro da semente até o momento da colheita. Para quantificar a irrigação foi instalado um sistema de controle de irrigação (volume de água) em um determinado espaço de tempo (Figura 2).

Figura 2 - Sistema de controle de irrigação no período de 1 min, com cinco repetições

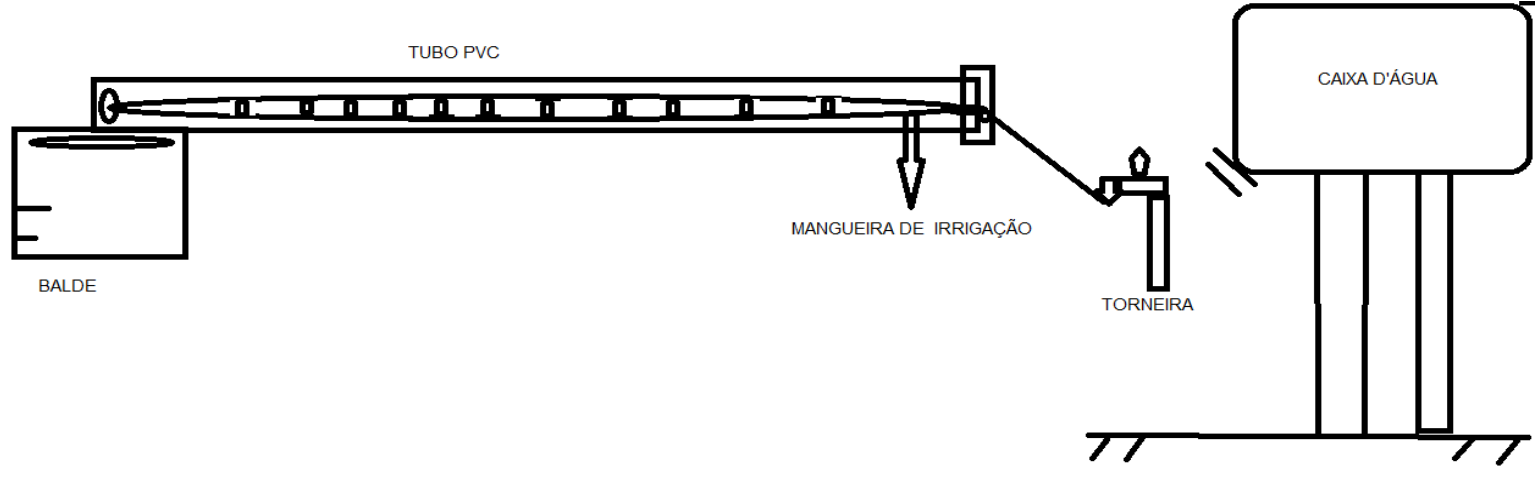

Os materiais utilizados foram tubo PVC com 32,28 metros de comprimento e com diâmetro de 50 milímetros; um balde com medidas até 20 litros; e a mangueira de irrigação com pressão $1 \mathrm{kgf} / \mathrm{cm}^{2}$. Com a ajuda de uma corda foi colocada a mangueira dentro do tubo PVC, sendo uma das pontas dela anexada a uma mangueira comum, responsável pelo transporte da água que sai da torneira para o tubo. 
Do outro lado, cavou-se um buraco no solo para colocar o balde. Ao ligar a torneira, a água que sai da mangueira de irrigação é convergida dentro do tubo e escorre para o balde no período cronometrado de 1 minuto com repetição de cinco vezes para se obter uma média do volume de água escoado por minuto (Figura 3).

Figura 3 - Sistema adotado para se obter o modelo de monitoramento

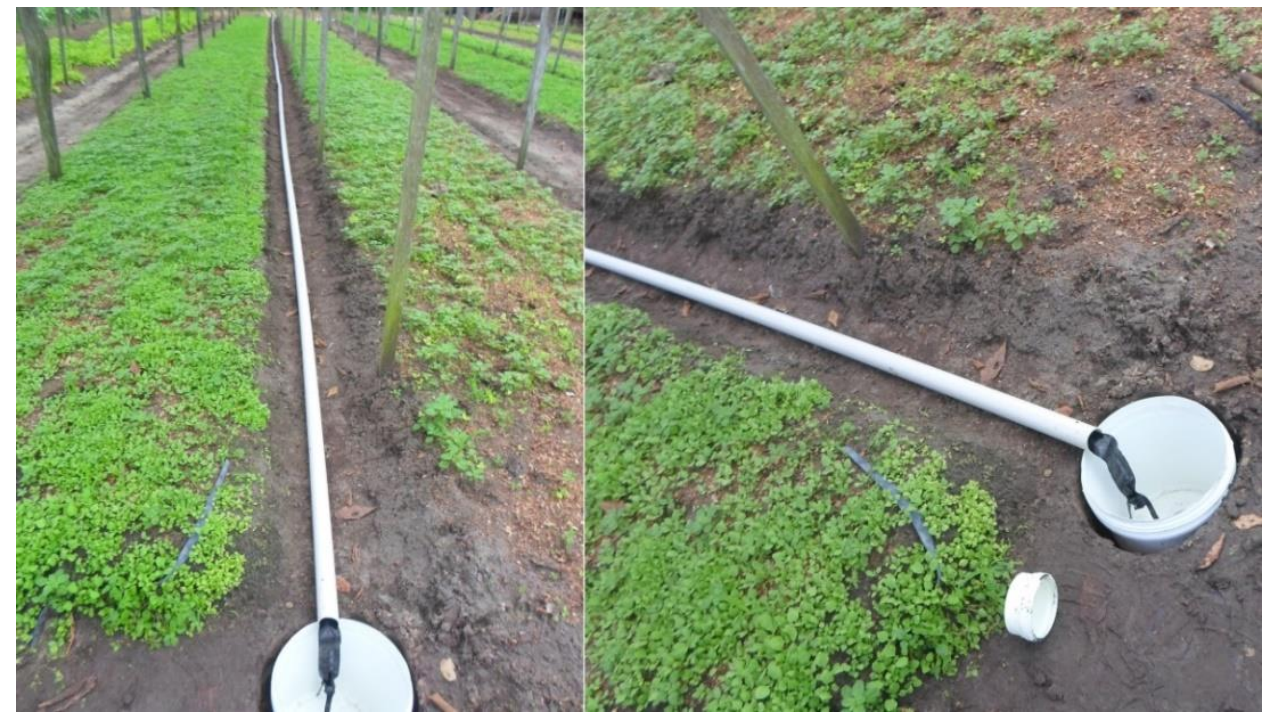

Fonte: Arquivo Pessoal

Para ter um valor de confiança da quantificação da água de irrigação, foram repetidas cinco vezes o sistema de medição no mesmo intervalo de tempo, pois o tempo médio de irrigação dos 50 canteiros é de uma hora. Adotou-se um minuto, que representa os 10 minutos de irrigação que é gasto aproximadamente todos os dias para cada canteiro. Tendo a média $\overline{\mathrm{x}}=11,4 \pm 0,3$ e a variância $\sigma^{2}=0,1$ calcula-se o intervalo de confiança- IC de $95 \%$.

$11,4-1,96(0,1 / \sqrt{ } 5) \leq \mu \leq 11,4+1,96(0,1 / \sqrt{ } 5)$

$\operatorname{IC}(\mu ; 0,95)=(11,31 ; 11,48)$

Esse resultado significa que existem $95 \%$ de chances de que cada 100 repetições do processo gere resultados dentro desse intervalo de 11,31 litros a 11,48 litros. No entanto, vale ressaltar que em virtude da mangueira irrigar dois canteiros ao mesmo tempo, optou-se pela divisão por dois o valor d'água utilizada na irrigação. Para sistematizar os dados considerou-se a irrigação dividida-ID para a mangueira entre os dois canteiros, e irrigação total-IT para a mangueira posta em cima do canteiro (Figura 4). Em seguida, começou o controle do tempo de irrigação para cada espécie de hortaliça durante trinta e cinco dias. Com isso, calculou-se o volume total de água utilizada em cada fase do ciclo de vida das plantas. 
Figura 4 - Formas de irrigação observadas: A: Irrigação Total-IT; B: Irrigação dividida-ID

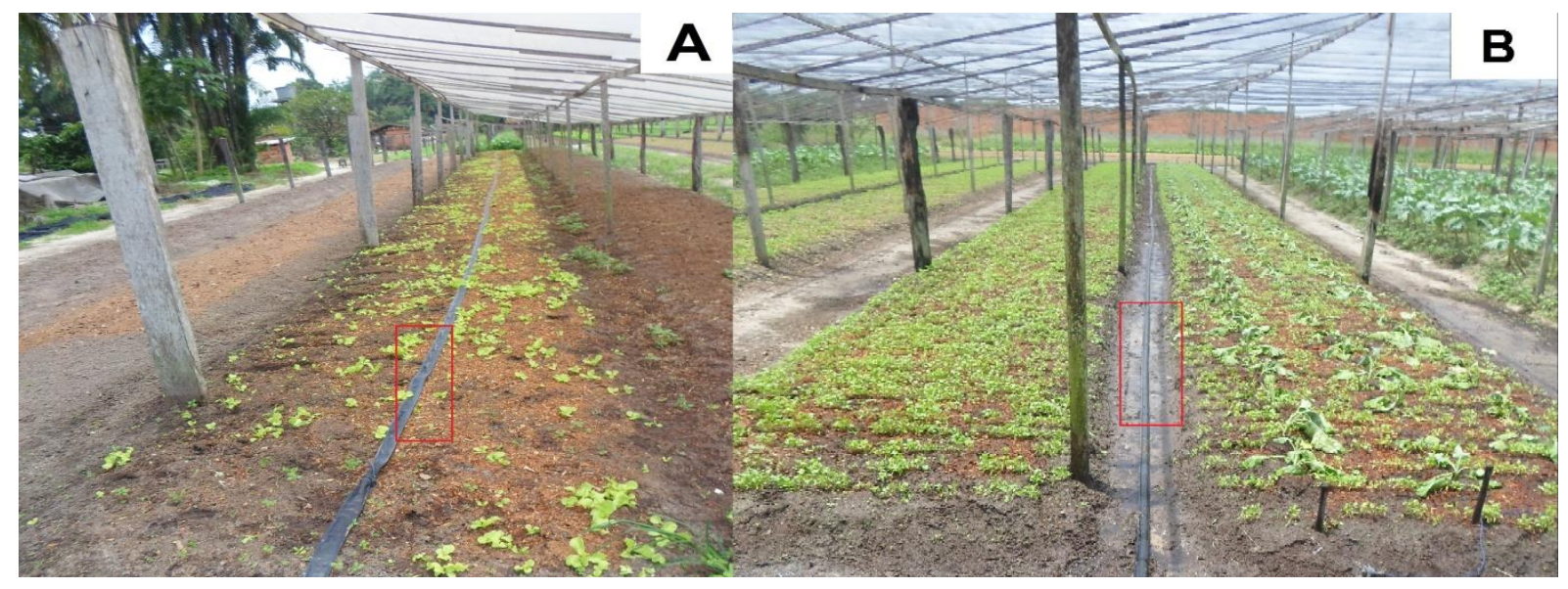

Fonte: Arquivo Pessoal

Além disso, em alguns dias do monitoramento foi usada uma mangueira comum com vazão de 15 litros por minuto. Esse tipo de irrigação foi denominada de irrigação $M$, ou seja, irrigação com a mangueira.

\subsection{Classificação das fases do ciclo de vida das hortaliças em estudo}

Com o intuito de ter um melhor monitoramento das hortaliças coentro e alface foram classificados de acordo com o ciclo de vida: no período de 1-8 dias, considerou-se como fase germinativa (Figura 5). Este é o tempo necessário para a planta germinar (MAROUELLI, 2007). A fase do nascimento e início do desenvolvimento, classificou-se como período vegetativo 9-35-dias (MAROUELLI, 2007).

Morouelli (2007) destaca que as hortaliças folhosas como alface e coentro, quando cultivadas para alimento são retiradas ainda no estágio vegetativo, se o objetivo do cultivo for retirar sementes tinha que esperar mais duas fases: a produtiva e a de maturação.

Figura 5 - A: Canteiro de hortaliça coentro 8 dias; B: Visão mais aproximada do coentro 8 dias

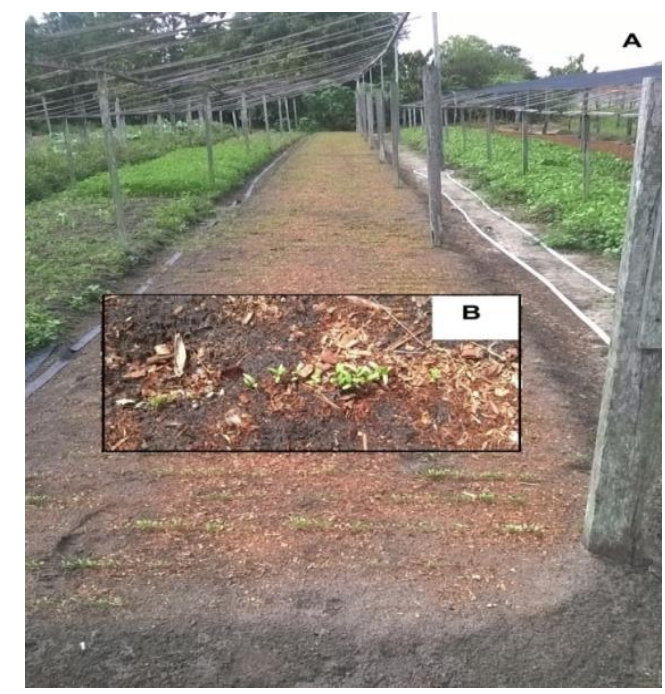

Fonte: Arquivo Pessoal 


\subsection{Evapotranspiração da cultura $-\mathbf{E T}_{\mathbf{C}}$}

A evapotranspiração da cultura-ETc é a quantidade de água evapotranspirada por uma planta no crescimento natural sem problemas com falta de umidade, luz solar, fertilidade ou qualquer outro fator (VICENTE; VICENTE, 2004).

Em virtude das dificuldades de quantificar dados $\mathrm{ET}_{\mathrm{C}}$ por medições diretas e precisas no campo, emprega-se a seguinte equação que é método padrão da FAO (Organização das Nações Unidas para Agricultura e Alimentação):

$$
\mathrm{ET}_{\mathrm{c}}=\mathrm{ET}_{\mathrm{o}} * \mathrm{~K}_{\mathrm{c}}
$$

onde,

$\mathrm{ET}_{\mathrm{c}}=$ Evapotranspiração da cultura $(\mathrm{mm} / \mathrm{dia})$

$\mathrm{ET}_{\mathrm{o}}=$ Evaporação de referência $(\mathrm{mm} / \mathrm{dia})$

$\mathrm{K}_{\mathrm{c}}$ : Coeficiente da cultura

Essa equação relaciona a evapotranspiração de referência pelo coeficiente de cada cultura determinada de forma empírica e deve ser usada em todas as fases dos ciclos de vida da planta (VICENTE; VICENTE, 2004).

$\mathrm{O}$ valor de $\mathrm{K}_{\mathrm{c}}$ e $\mathrm{ET}_{\mathrm{o}}$ vai mudar de acordo com a região, o primeiro pode ser encontrado na literatura, mas com critérios de semelhanças das regiões (SOUZA, 2011), já para o segundo são adotadas equações, dentre elas a FAO destaca: Penman-Monteith, Hargreaves, Camargo, Makkink, Jensen-Haise e Radiação Solar.

Neste trabalho foi usada a Equação de Hargreaves, sabendo-se que nas regiões com carência no banco de dados, como é o caso do trabalho, essa é a equação mais adequada, pois possui menor número de variáveis (ALLEN et al., 2006).

Abaixo a equação de Hargreaves para calculo de $\mathrm{ET}_{\mathrm{o}}$

$\mathrm{ET}_{\mathrm{o}}=0,0135 \mathrm{Rs}^{*}(\mathrm{~T}+17,8)$

onde,

$\mathrm{T}=$ temperatura média $\left({ }^{\circ} \mathrm{C}\right)$

Rs = radiação solar (mm dia-1)

Para o calculo da radiação solar utiliza-se a equação:

$\mathrm{Rs}=\mathrm{krs} \sqrt{\mathrm{Tmax}-\mathrm{Tmin}} * \mathrm{R}_{\mathrm{a}}$

onde,

$\mathrm{R}_{\mathrm{s}}=$ radiação solar

$\mathrm{K}_{\mathrm{rs}}=$ coeficiente de correção para região costeira

$\mathrm{T}_{\max }=$ temperatura máxima

$\mathrm{T}_{\min }=$ temperatura mínima

$\mathrm{R}_{\mathrm{a}}=$ radiação extraterrestre

Os dados de coeficientes de Kc foram encontrados na literatura: para o coentro foram usados coeficientes de cultura- kc encontrado por Silva, Tavares e Souza (2013) no município de Itabaiana-SE, sendo 0,82 para fase germinativa e/ou inicial e 1,03 para fase vegetativa e/ou média. A temperatura média anual do município é de $24,7^{\circ} \mathrm{C}$ (SANTOS; MACHADO, 2012), próxima a de Belém que chega a $26^{\circ} \mathrm{C}$ (OLIVEIRA; COUTURIER; BESERRA, 2003). Para o alface foram usados coeficientes de cultura - kc encontrado por Lima (2007), no município de Seropédica-RJ, sendo 0,7 para fase germinativa e/ou inicial 
e 0,85 para fase vegetativa e/ou média. A classificação climática de acordo com Koppe para região é de Aw (LIMA, 2007), mesma classificação adotada para Belém.

Os dados utilizados na equação Hargreaves e em seguida na equação padrão da FAO, foram obtidos no Instituto Nacional de Meteorologia (INMET) do município de Belém, uma vez que não existem dados para o município em estudo, foi escolhido Belém, sabendo-se que Benevides pertence à região metropolitana de Belém de acordo com Instituto Brasileiro de Geografia e Estatística (IBGE, 2014).

\subsection{Quantidade de água após a colheita da hortaliça}

A determinação da quantidade de água que está presente nas hortaliças após a colheita foi realizada através da divisão do canteiro em quatro pontos para tornar adequada a geração dos resultados (Figura 6).

Figura 6 - Representação esquemática de como foram coletadas as amostras de cada ponto para análise do teor de umidade das hortaliças

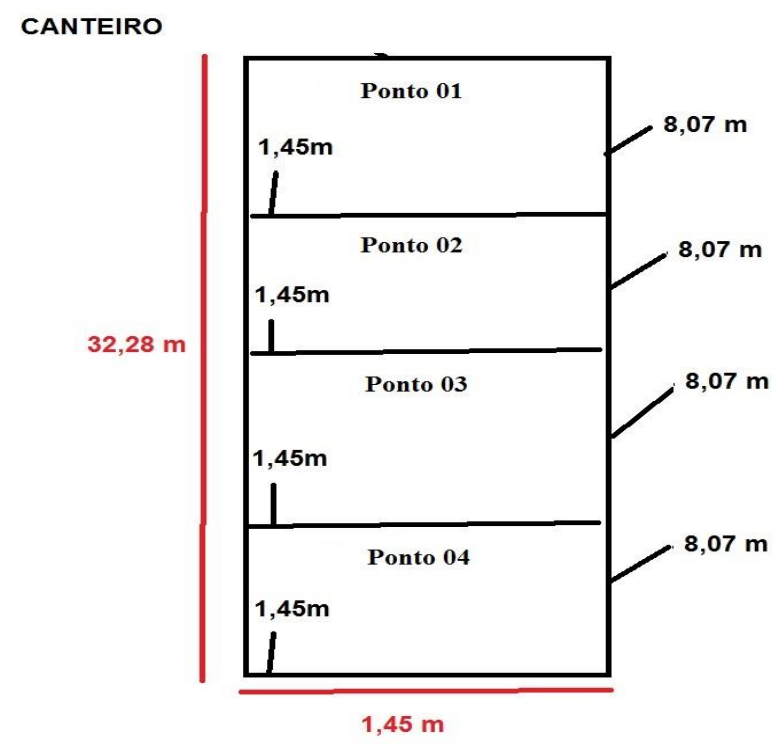

Adotou-se à norma do Instituto Adolfo Lutz (2008), que através do cálculo do teor de umidade pode-se ter o valor aproximado da água embutida nos alimentos. A metodologia trata-se do aquecimento direto da massa a $105^{\circ} \mathrm{C}$ até ter um valor constante, a massa aquecida deve ser no intervalo de $1,5 \mathrm{~g}$ a $2 \mathrm{~g}$. Adolfo Lutz (2008) realiza o processo com a estufa a $105^{\circ} \mathrm{C}$ e após o valor se tornar constante é realizado cálculos para determinar a porcentagem de umidade, porém neste trabalho foi utilizada a Balança Termogravimétrica marca OHAUS, que também aquece as amostras a $105^{\circ} \mathrm{C}$ com lâmpada infravermelho e tem como vantagem a geração direta do cálculo de umidade.

\subsection{Determinação do valor monetário da água virtual}

Para determinar o valor da água virtual foram utilizados os parâmetros estabelecidos pela Companhia de Saneamento do Pará (COSANPA) com seus critérios de cobrança por metros cúbicos d'água. 
A COSANPA tem um sistema de cobrança de água baseado dos critérios de classificação do consumidor de acordo com o artigo $1^{\circ}$ da lei ordinária 11.445/2007 que estabelece diretrizes nacionais para o saneamento básico, onde existem as categorias: residência, comercial, industrial e o público. Essas categorias são classificadas de acordo com os pontos de saídas d'água na sua quantidade, localização do imóvel e outros critérios não fornecidos pela instituição.

A propriedade estudada possui 13 pontos de saída d'água para conectar as mangueiras de irrigação, onde apenas esses pontos, já a classifica como indústria de acordo com a COSANPA. Outro ponto abordado pela instituição é a cobrança dos serviços de esgoto, em virtude da lei ordinária 11.445/2007, artigo 29 que diz: “Os serviços públicos de saneamento básico terão a sustentabilidade econômico-financeira assegurada, sempre que possível, mediante remuneração pela cobrança dos serviços" (PRESIDÊNCIA DA REPÚBLICA, 2007), a cobrança é devida com $60 \%$ do valor do consumo d'água.

\section{RESULTADO E DISCUSSÃO}

Apesar de a região estar no período mais quente do ano, no caso dos meses de setembro e outubro, foi observado que durante os 35 dias, em dez choveu, o equivalente a 28,57\% do tempo monitorado. Nesses dias não houve irrigação e dependendo da umidade do solo, a irrigação continua suspensa, foi o que ocorreu nos dias: $08,09,11,15$ e 23 de outubro, o que representa 14,29\% dos dias monitorados. Com isso, obtiveram-se 20 dias de irrigação que é $57,14 \%$ do tempo necessário para a hortaliça completar seu ciclo de vida (Figura 7).

Figura 7 - Porcentagem de: Chuva; solo úmido; irrigação durante 35 dias de crescimentos das hortaliças

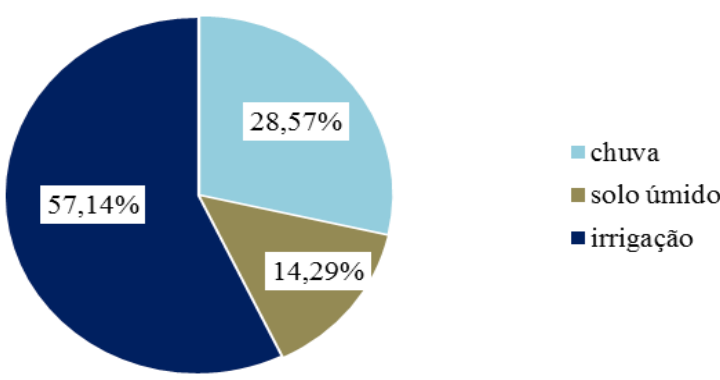

Com vinte dias de irrigação, um canteiro de alface gastou 3664,8 litros de água, já o coentro teve um total de 2961 litros d'água. Com relação aos tipos de mangueiras utilizada para irrigação, observou-se que a mangueira comum gasta maior volume de água por minuto sendo 15 litros por minuto, já a de outra marca tem um consumo menor que em média é 11,4 litros por minuto.

\subsection{Procedimentos realizados no laboratório}

As amostras de cada ponto do canteiro de alface e coentro foram retiradas no dia 31 de outubro de 2014 às 7h:15 min e transportados para o laboratório dentro de sacos limpos, sem lavar e nem passar 
por refrigeração. No laboratório de físico-química às 9h:30min, realizou-se a limpeza das hortaliças com auxílio de um pincel. Em seguida foi pesado e triplicado os valores no intervalo de $1,93 \mathrm{~g}$ a $2 \mathrm{~g}$ para o coentro e $1,92 \mathrm{~g}$ a $2 \mathrm{~g}$ para o alface na balança termogravimétrica.

Entre 25 a 35 minutos o peso se estabilizou, tempo esse que deixou as amostras desidratadas e a partir disso o equipamento disponibiliza o teor de umidade.

Feito isso, foram obtidos 24 dados de teor de umidade 12 para alface e 12 para o coentro gerando 4 médias por espécie (Tabela 1). A partir disso retirou-se as médias totais por canteiro tendo resultado de $86,93 \% \pm 0,5$ e $91,36 \% \pm 0,3$ de coentro e alface, respectivamente, valores próximos de $100 \%$ como estimado por Filgueira (2013).

Tabela 1 - Médias do teor umidade

\begin{tabular}{lll}
\hline & Coentro & Alface \\
Média $1^{\circ}$ área do canteiro & $88,12 \%$ & $91,33 \%$ \\
Média $2^{\circ}$ área do canteiro & $87,66 \%$ & $90,86 \%$ \\
Média $3^{\circ}$ área do canteiro & $85,60 \%$ & $90,79 \%$ \\
Média $4^{\circ}$ área do canteiro & $86,34 \%$ & $92,48 \%$ \\
Média total & $86,93 \%$ & $91,37 \%$ \\
\hline
\end{tabular}

Fonte: Dados da pesquisa

Cada canteiro produz, em média, 300 maços de coentro e alface, onde um maço pesa, em média, $403,03 \mathrm{~g}$ e $451,66 \mathrm{~g}$, respectivamente. Se considerar o teor de umidade encontrado no laboratório (Tabela 1), o consumidor recebe apenas $52,70 \mathrm{~g}$ de coentro e $38,99 \mathrm{~g}$ de alface de matéria seca. No entanto, essa quantidade de água que chega à casa do consumidor ainda não é o valor de água virtual, pois a quantidade de água embutida no maço das hortaliças tem valor monetário, já que ela completa o peso do maço em mais de $85 \%$.

\subsection{Quantidade de água gasta nos ciclo de vida do coentro e alface}

No ciclo germinativo do coentro foi gasto 798 litros de água o que é 250,8 litros a menos gasto no mesmo ciclo do alface que teve 1.048,8 litros. Já na fase vegetativa o coentro apresentou um aumento da sua demanda d'água que passou para 2.163 litros. $\mathrm{O}$ alface necessitou 2.616 litros de água no $2^{\circ}$ período de vida o que manteve um alto índice de água em todo o seu ciclo.

No estágio vegetativo, as duas hortaliças tiveram maior volume de água gasta, o que pode ser justificado, em virtude desse período ser mais longo, com 27 dias, enquanto o primeiro tem apenas 8 dias. Com isso, os valores de água virtual encontrada, ou seja, sem a retirada da evapotranspiração das culturas coentro e alface, foram: 2.961 litros e 3.664,8 litros, respectivamente (Figura 8). 
Figura 8 - Gráfico do volume irrigado por ciclo vida de germinativo-1-8; vegetativo 9-35 de alface e coentro e a quantidade de água total consumida.

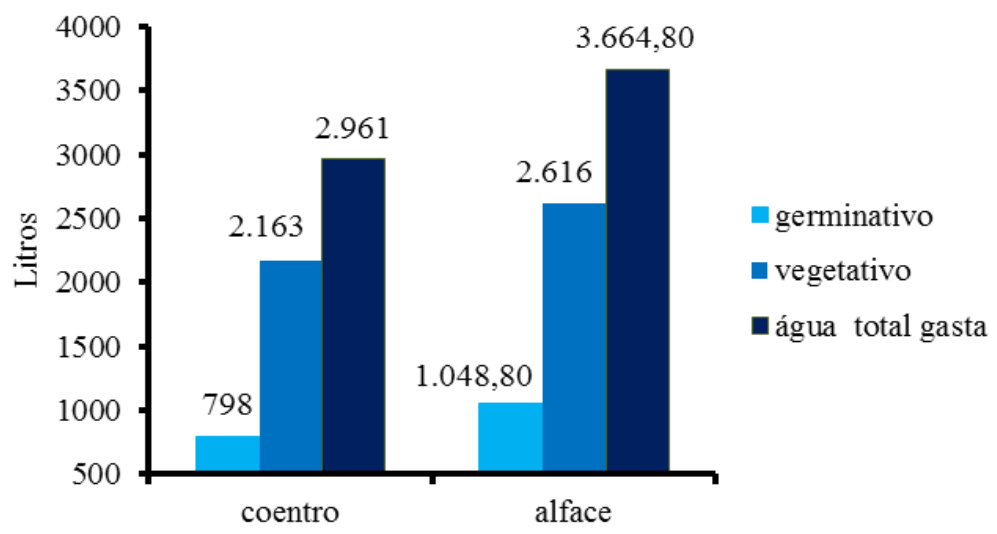

O volume de água gasto por canteiro de coentro e alface, sabendo que a propriedade possui 34 canteiros de coentro e 10 de alface, contabiliza um total de 100.674 litros e 36.648 litros de água, respectivamente, o que soma um total gasto na propriedade de 137.322 litros, fora os 6 canteiros de outro tipo de hortaliça. A média nacional de consumo de água por família é $15 \mathrm{mil}$ litros por mês (VICTORINO, 2007), neste caso, daria para abastecer 9,15 famílias durante um mês.

De acordo com o IBGE (2014) estima-se, para o ano de 2014, que a população de Benevides tenha 57.393 habitantes. Com isso, o volume gasto de água na propriedade com os 44 canteiros têm aproximadamente 2,39 litros de água por habitante de Benevides previsto para 2014.

\subsection{Quantidade de água evapotranspirada das culturas coentro e alface}

Com a aplicação da equação de Hargreaves calculou-se em seguida a equação padrão da FAO, com isso, obteve-se os resultados de evapotranspiração de cultura (ETc) dos ciclos germinativo e vegetativo das duas hortaliças (coentro e alface), o resultado foi obtido através da soma dos valores diários de ETc de cada período, ou seja, os primeiros oitos dias foram calculados sua ETc e somados, isso é o equivalente ao primeiro ciclo, por seguinte, somou-se os vinte e sete dias restantes que também foi feito seus cálculos de Etc diários, que o resultado da soma equivale ao segundo ciclo.

As médias diárias do coentro foram de $11,7 \pm 0,47 \mathrm{~mm} / \mathrm{dia}$ no período germinativo e $14,63 \pm 0,63 \mathrm{~mm} /$ dia no período vegetativo. $\mathrm{O}$ alface apresentou as médias diárias de $9,98 \pm 0,4 \mathrm{~mm} /$ dia no período germinativo e $11,96 \pm 0,56 \mathrm{~mm} /$ dia no período vegetativo. Os valores somados foram $93,48 \mathrm{~mm} / \mathrm{dia}$ e 79,8 mm/dia no período germinativo para coentro e alface, respectivamente, já para o fase vegetativa teve valores de $393,71 \mathrm{~mm} /$ dia para o coentro e $324,91 \mathrm{~mm} /$ dia para o alface (Tabela 2).

Tabela 2 - Valores total evapotranspiração de cultura por período do ciclo de vida do coentro e alface

\begin{tabular}{lll}
\hline Espécie & Ciclo & $\mathrm{Et}_{\mathrm{c}}(\mathrm{mm} / \mathrm{dia})$ \\
Coentro & Germinativo & 93,48 \\
Coentro & Vegetativo & 393,71 \\
Alface & Germinativo & 79,80 \\
Alface & Vegetativo & 324,91 \\
\hline
\end{tabular}

Fonte: Dados da pesquisa 
Portanto, o valor de água evapotranspirada na cultura do coentro durante os 35 dias de monitoramento foram de 487,19 mm/dia, a de alface somaram 404,71 mm/dia. Esse valor representa a perda de água para o meio ambiente que as culturas têm ao longo do seu ciclo de vida, essa água não é considerada água virtual, uma vez que ela retorna ao ciclo natural, ou seja, não fica incluída no produto, ela retorna como chuva ou de outra forma do ciclo hidrológico.

\subsection{Determinação da água virtual}

Os fatores ambientais podem interferir e/ou dificultar os resultados da quantidade de água virtual que entra no ciclo de vida da planta, pois parte da água que entra no ciclo é perdida para o ambiente na forma de evapotranspiração, ou seja, volta para o ciclo hidrológico. Com isso, foi retirado do volume de água gasto durante o ciclo de vida a quantidade de água que é evapotranspirada por cada cultura, assim, gerando o valor da água virtual para o coentro e o alface por canteiro (Tabela 3).

Tabela 3 - Valores de água: gasta, evapotranspirada por cultura e virtual

\begin{tabular}{llll}
\hline Espécies & água gasta & água ETc & água virtual \\
& (litros) & (litros) & (litros) \\
Coentro & 2.961 & 487,19 & $2.473,81$ \\
Alface & $3.664,8$ & 404,71 & $3.260,09$ \\
\hline
\end{tabular}

Fonte: Dados da pesquisa

Tendo o valor de água virtual, são obtidos novos volumes de quantidade d'água gasto na propriedade, mas agora na forma virtual (Figura 9) e que somados 44 canteiros, ressaltando que são 34 de coentro e 10 de alface, o novo volume total gasto é 116.710,44 litros de água. Pode-se observar que são perdidos apenas 20.611,56 litros para o ambiente, equivalente a $15,01 \%$ do volume gasto sem a retirada da perda para o ambiente que era de 137.322 litros.

Figura 9 - Gráfico do volume irrigado por ciclo vida de germinativo-1-8; vegetativo 9-35 de alface e coentro e o valor de água virtual calculada, que é a soma dos ciclos de cada cultura

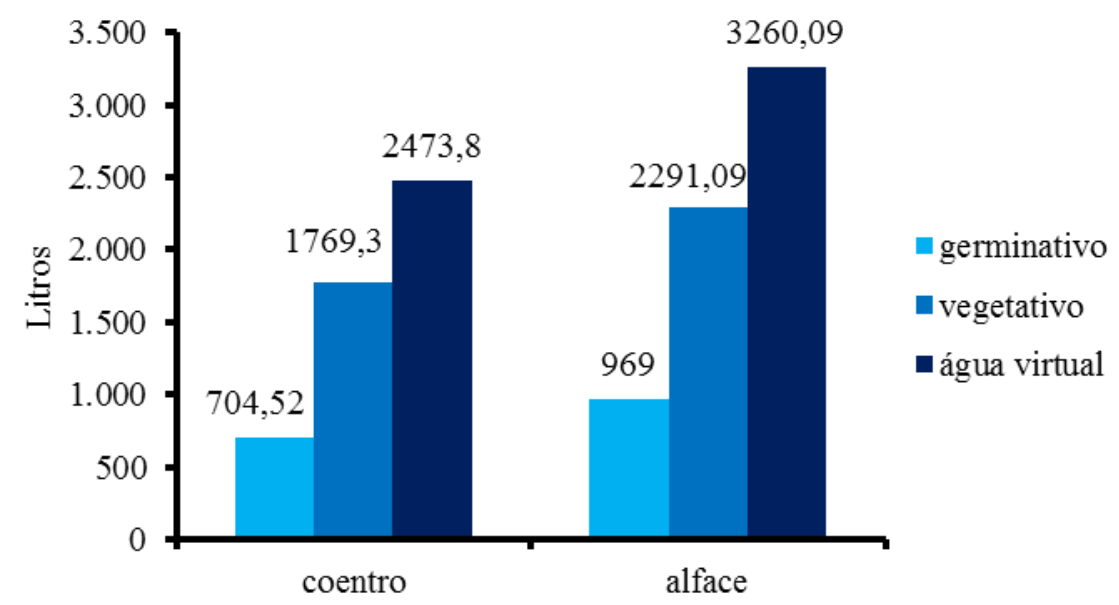


Portanto, uma vez que se estima 57.393 habitantes para o ano de 2014 no município de Benevides, em apenas uma propriedade esta tendo um gasto na forma virtual, o equivalente a 2,03 litros de água por habitante. Essa água é perdida durante a produção, pois ela não é embutida no preço final, o que vem a definir o termo de "Virtual Water" ou água virtual, pois ela existe, como apresentada nessa pesquisa com o volume de 116.710,44 litros, porém não é quantificada monetariamente no produto ofertado.

Portanto, existe uma perda de 116.710,44 litros de água na forma virtual durante a produção das hortaliças coentro e alface, onde o município Benevides-PA esta deixando de ganhar esse beneficio monetário.

\subsection{Valor monetário da água virtual}

O volume de água virtual gasto na propriedade foi de 116.710,44 litros, o equivalente a 141,45 metros cúbicos, o valor a ser pago é de $\mathrm{R} \$ 760,28$ mais $\mathrm{R} \$ 456,17$ de serviços de esgoto somando um valor total de $\mathrm{R} \$ 1.216,45$ reais.

Sabendo-se que cada canteiro produz 300 maços entende-se que para um maço de coentro gastase 8,25 litros e para o alface 10,87 litros, se for considerado o valor monetário total cobrado pela água virtual de cada espécie e dividir por 300 marços, o valor monetário a ser embutido no março de água virtual será de 0,08 para o coentro e 0,11 para o alface (Tabela 4).

Tabela 4 - Dados da água virtual

\begin{tabular}{lcccc}
\hline Espécie & $\begin{array}{c}\text { Água virtual } \\
\text { Por canteiro } \\
\text { (litros) }\end{array}$ & $\begin{array}{c}\text { Preço água } \\
\text { virtual } \\
\text { Por canteiro } \\
\text { (reais) }\end{array}$ & $\begin{array}{c}\text { Quantidade de } \\
\text { água virtual por } \\
\text { maço(l) }\end{array}$ & Preço por maço (reais) \\
Coentro & $2.473,81$ & 25,78 & 8,25 & 0,08 \\
Alface & $3.260,09$ & 33,98 & 10,87 & 0,11 \\
\hline
\end{tabular}

Fonte: Dados da pesquisa

O maço do coentro é vendido em atacado e varejo, sendo os valores de $\mathrm{R} \$ 0,80$ e $\mathrm{R} \$ 3,00$, respectivamente. Já o alface é vendido a $\mathrm{R} \$ 0,70$ no atacado e $\mathrm{R} \$ 2,00$ no varejo. Com o valor monetário da água virtual o preço do maço de coentro e alface tem seus novos preços com um aumento de $\mathrm{R} \$ 0,08$ no coentro e R \$ 0,11 no alface (Tabela 5).

Tabela 5 - Valores monetários o maço de coentro e alface

\begin{tabular}{ccccc}
\hline Espécie & $\begin{array}{c}\text { Maço atacado } \\
(\mathrm{R} \$)\end{array}$ & $\begin{array}{c}\text { Maço varejo } \\
(\mathrm{R} \$)\end{array}$ & $\begin{array}{c}\text { Novo preço } \\
\text { atacado }\end{array}$ & $\begin{array}{c}\text { Novo preço varejo } \\
(\mathrm{R} \$)\end{array}$ \\
& & & $(\mathrm{R} \$)$ & 3,88 \\
Coentro & 0,80 & 3,00 & 0,88 & 2,11 \\
Alface & 0,70 & 2,00 & 0,81 & \\
\hline
\end{tabular}

Fonte: Dados da pesquisa 
A água virtual contabilizada no produto tem importância econômica, ambiental e social, sendo assim o produtor tenderá a procurar alternativas para diminuir o custo com a água, que causa uma diminuição nos gastos d'água na irrigação, indo a favor do meio ambiente. Desta maneira, a sociedade também terá benefícios por ter por mais tempo o recurso hídrico e o produto com um preço acessível, mas agora sustentável. Por outro lado, o produtor terá um produto mais sustentável em todo o seu ciclo de vida.

\section{CONCLUSÃO}

Conclui-se que o valor da água virtual embutido nas hortaliças coentro e alface por canteiro foi de 2.473,81 litros e 3.260,09 litros, respectivamente, o que representa 8,25 litros por março de coentro e 10,87 por março de alface. Em valor monetário as hortaliças tiveram um aumento de $\mathrm{R} \$ 0,08 / \mathrm{mc}$ para cada março de coentro e $\mathrm{R} \$ 0,11$ para cada março de alface.

\section{REFERÊNCIAS}

ALLAN, J. Virtual water - the Water, Food and Trade Nexus Useful conceptor Misleading Metaphor? IWRA Water International, v. 8, p. 4-11, 2003.

ALLEN, R. G.et al. FAO Irrigation and Drainage. Crop Evapotranspiration, v. 35, n. 56, 2006 (guidelines for computing crop water requirements).

CARMO, R. L.et al. Água Virtual, escassez e gestão: o Brasil como grande "Exportador" de água. Ambiente \& Sociedade, v.10, 2007.

CARMO, R. L.et al. Água virtual: o Brasil como grande exportador de recursos hídricos. Ambiente \& Sociedade, v.10, 2006.

DOWBOR, L. Economia de Água. In: DOWBOR, L.; TAGNIN, R. A. (orgs.). Administrando a Água como se Fosse Importante: Gestão Ambiental e Sustentabilidade. São Paulo: SENAC, 2005.

Food and Agriculture Organization of the United Nations - FAO. Tackling through livestock: A global assessment of emissions and mitigation opportunities. Rome: Food and Agriculture Organization of the United Nations (FAO), 2013.

FILGUEIRA, F. A. R. Novo manual de Olericultura: agrotecnologia moderna na produção e comercialização de hortaliças. 3 ed. rev. e Amp. Viçosa, Minas Gerais, 2013.

FURLANI, P. R.; PURQUERIO, L. F. V. Nutrição de Plantas: diagnose foliar em hortaliças, 2010.

INSTITUTO ADOLFO LUTZ. Normas Analíticas do Instituto Adolfo Lutz: Métodos químicos e físicos para análise de alimentos. 3. Ed., v.1, São Paulo: IMESP, 2008.

IBGE- INSTITUTO BRASILEIRO DE GEOGRAFIA E ESTATÍSTICA. Cidades. Disponível em: < http://www.cidades.ibge.gov.br> Acesso em jun 2014, 2014.

IDESP - INSTITUTO DE DESENVOLVIMENTO ECONÔMICO, SOCIAL E AMBIENTAL DO PARÁ. Benevides, 2011.

LIMA, M. E. Avaliação do desempenho da cultura da alface (Lactuca sativa) cultivada em sistema orgânico de produção, sob diferentes lâminas de irrigação e coberturas do solo. 2007. Dissertação (Mestrado em Ciências). Seropédica, Rio de Janeiro. 
MAROUELLI, W. A. Irrigação em Campos de Produção de Sementes de Hortaliças. Brasília: Embrapa, 2007.( Circular Técnica EMBRAPA).

MEIO AMBIENTE, 2010. Disponível em:< http://www.meioambiente.pr.gov.br> Acessado em jun 2014.

OJIMA, A. L. R. O.et al. A (Nova) Riqueza das nações: Exportação e importação brasileira da água virtual e os desafios frente às mudanças climáticas. Tecnologia \& Inovação Agropecuária, São Paulo, v.1, 2008.

OLIVEIRA M. S. P.; COUTURIER, G.; BESERRA, P. Biologia da polinização da palmeira tucumã (Astrocaryum vulgare Mart.) em Belém, Pará, Brasil. Acta Bot. Bras. [online], v.17, 2003. disponível em http://www.alice.cnptia.embrapa.br/bitstream/doc/407027/4/17703.pdf

Acessado em nov 2014.

PRESIDÊNCIA DA REPÚBLICA, 2007. Disponível em http://www.planalto.gov.br/ccivil_03/_ato20072010/2007/lei/111445.htm

Acessado em nov 2014.

REBOUÇAS, A. C. Água no Brasil: abundância, desperdício e escassez. Bahia Análise \& Dados, Salvador, v. 13, 2003.

SILVA, V. P. R.; TAVARES, A. L.; SOUSA, I. F. Evapotranspiração e coeficientes de cultivo simples e dual do coentro. Horticultura Brasileira, v. 31, n. 2, abr - jun 2013.

SANTOS, R. S.; MACHADO, C. S. Geologia e planejamento territorial. Seminário do GEOPLAN, Sergipe, v. 4, 2012.

SOUZA, A. S. P. Avaliação de métodos de estimativa da evapotranspiração de referência para fins de manejo de irrigação. Dissertação (Mestrado em Meteorologia do Instituto de Geociências), Centro de Ciências Matemáticas e da Natureza da Universidade Federal do Rio de Janeiro, 2011.

VICENTE, A. S. C.; VICENTE, S. E. I. Proposta para Manejo da Irrigação. Belém, Amazônia Irrigação, 2004.

VICTORINO, C. J. A. Planeta água morrendo de sede: uma visão analítica na metodologia do uso e abuso dos recursos hídricos. Porto Alegre: EDIPUCRS, 2007. 
